Japan. J. Med. Sci. Biol., 30, 165-169, 1977

\title{
DEMONSTRATION OF CHOLESTEROL ESTERIFIED WITH POLYUNSATURATED FATTY ACIDS IN MYCOBACTERIA GROWN IN VIVO*
}

The presence of cholesterol in tubercle bacilli grown in vivo, but not in vitro, was first demonstrated by Youngner and Noll (1958). Asselineau (1966) explained that cholesterol of host origin would have been adsorbed on the bacillary surface. Kondo et al. (1970) confirmed the above observation with an additional finding that not a small amount of the bacillus-associated cholesterol were the esters with fatty acids. Unlike free cholesterol, such cholesterol esters were not removed efficiently from the bacilli by the extraction method of Fleischer, Fleischer and Stoechnius (1967), suggesting very close association of the latter lipid with the bacilli.

This finding led us to an assumption that the ester type of cholesterol might be an indication of macrophage-mycobacteria interaction. Our recent study (1976) showed that cholesterol esters were accumulated in the incubation mixture of virulent mycobacteria and uninduced (resident) peritoneal macrophages of normal mice. This phenomenon was observed in the environment of Hanks' solution without added serum, and a suggestive evidence indicated that polyunsaturated long-chain fatty acids might be concerned with cholesterol esterification. As an extension of this observation, this paper is to demonstrate the presence of cholesterol esterified with polyunsaturated fatty acids in mycobacteria harvested from the infected mouse lungs. By this approach, the above assumption will be given a further support.

Two hundred normal mice (ddY, male, $18 \mathrm{~g}$ ) were infected intravenously with $0.5 \mathrm{mg}$ of a kanamycin-resistant strain of $M$. bovis (Ravenel) grown on Sauton synthetic liquid medium. On days 1, 6, 9, 14, and 19 of infection, three mice each were sampled at random and killed to remove the lungs. The pooled lungs were homogenized with distilled water and a small portion of the homogenate was employed for enumeration of viable units by the method described elsewhere (Kanai and Kondo, 1971). The remaining major portion was subjected to lipid extraction with chloroform-methanol $(2: 1, \mathrm{v} / \mathrm{v})$; separation and quantitative determination of free and ester cholesterols were carried out as described before (Kondo and Kanai, 1976). The results shown in Fig. 1 indicate that the increase of cholesterol ester content in the mouse lung was correlated with the progress of infection as expressed by the time-course elevation of tissue viable counts.

On day 21 of infection when the remaining mice were in moribund condi-

* This investigation was supported partly by a Scientific Research Grant of the Ministry of Education. 


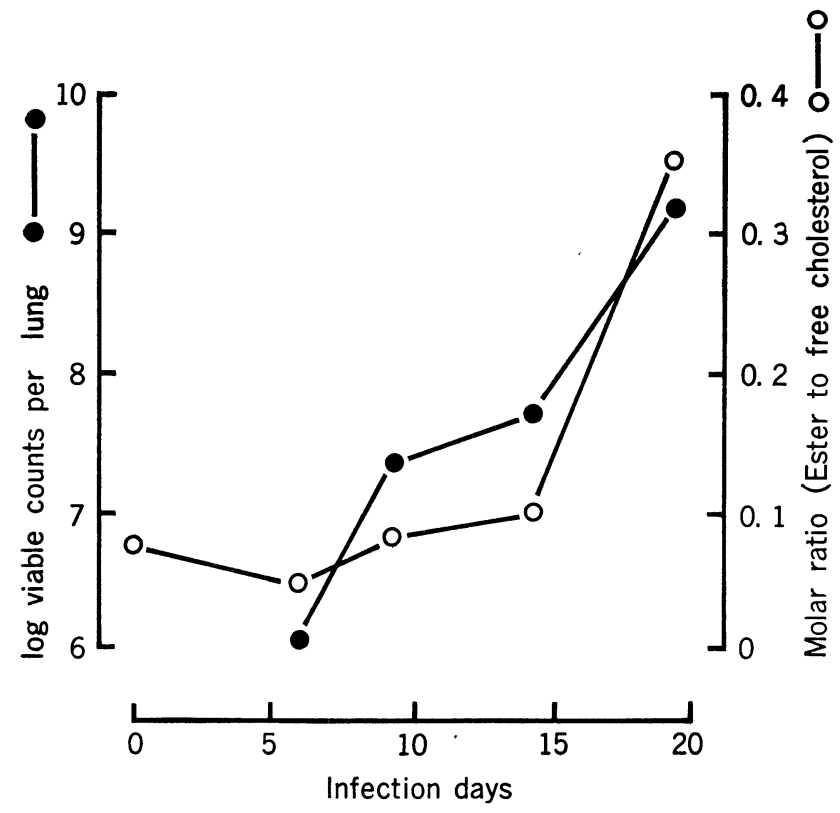

Fig. 1. Elevation of the molar ratio of ester to free cholesterol in the mouse lung tissue with the development of mycobacterial infection.

tion, all of them were sacrificed to remove the granulomatous lungs. The pooled fresh lungs were $144 \mathrm{~g}$ in total, and "in vivo bacilli" were separated therefrom by differential centrifugation of the homogenate and by the final treatment with trypsin (Kanai and Kondo, 1970). The suspension of "in vivo bacilli" thus purified was adjusted to the same turbidity as that of a 1-mg-per-ml suspension of the same strain grown on Sauton medium. Comparison was made regarding viability between these two bacillary suspensions. The result showed that the viable cells in the suspension of the in vivo bacilli were more than twice as much

\section{TABLE I}

Condenced presence of cholesterol esters in mycobacteria harvested and purified from the infected mouse lung homogenate

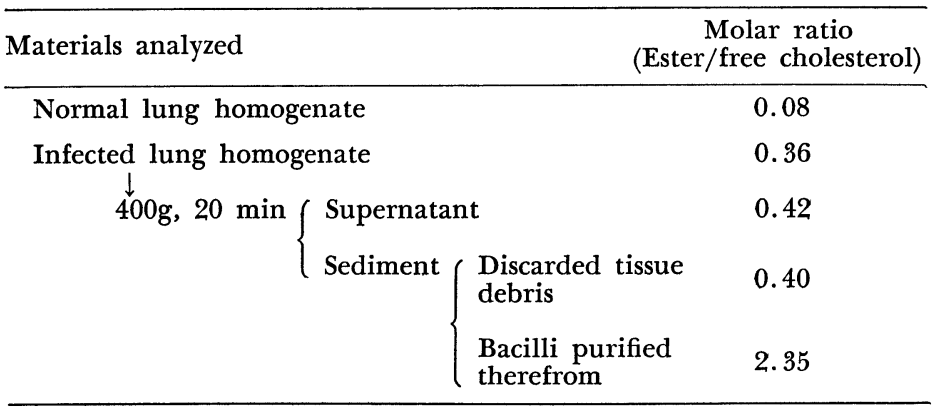


as that of the in vitro bacilli $\left(14 \times 10^{6} / 6 \times 10^{6}\right)$. This may indicate that the preparation of in vivo bacilli was satisfactory at least in bacteriological purity. Extraction and quantitative determination of free and ester cholesterols from this sample were carried out in reference to the starting lung homogenate and the tissue debris to be discarded during the purification procedure of "in vivo bacilli".

The results are shown in Table I. Interesting is the observation that the molar ratio of ester to free cholesterol is outstandingly high in the bacilli, even higher than the discarded tissue debris, despite the fact that mycobacteria do not have sterols and that the bacilli had been purified from the infected tissue as stated above. In other words, cholesterol esters were selectively concentrated by the procedure to purify the bacilli from the infected tissue. The most reasonable explanation will be that cholesterol esters were present in the close vicinity to the bacilli and become associated with them. This would be possible within mycobacteria infected macrophages in view of our previous study (Kondo and Kanai, 1976).

Quantitative determinations for free and ester cholesterols were conducted after they were separated on a thin layer plate of silica gel G. When the solvent system of heptane : ether : acetic acid (90:10:1) was employed for development instead of hexane : ether : acetic acid (90:10:1), the spot of cholesterol ester was often separated into two parts, the upper part taking a more reddish color reacting to heating after spray with Zlatkis reagent and the lower part taking a rather brown color. On the assumption that this phenomenon was due to mixture of

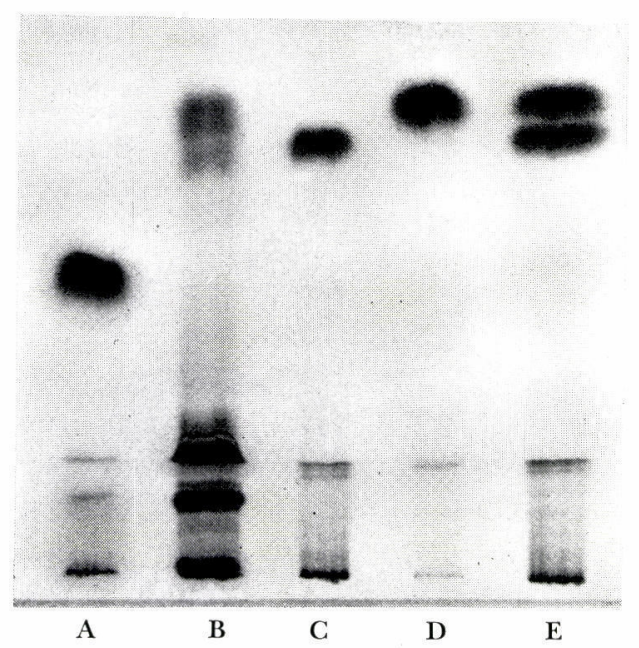

Fig. 2. Thin-layer chromatogram of the neutral fat fraction of $M$. bovis (Ravenel) grown in vivo on a silica gel $G$ plate developed with a solvent system of heptane : ether : acetic acid $(90: 10: 1)$ and colored by spray with Zlatkis reagent.

A : Methyl arachidonate $200 \mu \mathrm{g}$; B: Neutral fat of mycobacteria grown in vivo $1000 \mu \mathrm{g}$; C: Cholesteryl arachidonate $100 \mu \mathrm{g}$; D: Cholesteryl oleate $100 \mu \mathrm{g}$; E: Cholesteryl oleate plus cholesteryl arachidonate $100 \mu \mathrm{g}$ and $200 \mu \mathrm{g}$. 
various molecular species of cholesterol esters different in constituent fatty acids, thin-layer chromatography of the neutral fat fraction of the in vivo bacilli was conducted with cholesteryl oleate, cholesteryl arachidonate and methyl arachidonate as reference standard samples. The chromatograms shown in Fig. 2 present an evidence that the lower part of the ester spot represents cholesterol esterified with unsaturated longer-chain fatty acids. This was indicated not only by $\mathrm{Rf}$ value, but also by the Zlatkis reagent-induced color change of spot as stated above.

To confirm the molecular species of cholesterol esters, gas-liquid chromatography (GLC) was carried out with the sample extracted from the gel on a thinlayer plate localized with $\mathrm{I}_{2}$ vapor. Methylation of fatty acids and the conditions of GLC were described in previous papers (Kondo et al., 1971; Kondo and Kanai, 1974). As cholesterol esters to be compared with those obtained from the in vivo bacilli, two other samples were examined concomitantly, one being isolated from the glass-adherent cells of the mycobacteria-infected granulomatous lungs (Kondo and Kanai, 1976) and the other from infected mouse serum by extraction with chloroform-methanol $(2: 1, \mathrm{v} / \mathrm{v})$ and subsequent fractionation by thin-layer chromatography. The results are shown in Table II. Roughly speaking, unsaturated

TABLE II

Main fatty acid pattern (\%distribution) of cholesterol esters obtained from M. bovis

(Ravenel) grown in the mouse lungs, glass-adherent cells of infected mouse lungs, and infected mouse serum

\begin{tabular}{lrrrrrrrrrrc}
\hline \multirow{2}{*}{$\begin{array}{l}\text { Cholesterol } \\
\text { esters from }\end{array}$} & $\mathrm{C}_{14: 0}$ & $\mathrm{C}_{16: 0}$ & $\mathrm{C}_{16: 1}$ & $\mathrm{C}_{18: 0}$ & $\mathrm{C}_{18: 1}$ & $\mathrm{C}_{18: 2}$ & $\mathrm{C}_{18: 3}$ & $\mathrm{C}_{20: 1-3}$ & $\mathrm{C}_{20: 4}$ & $\begin{array}{c}\text { Unsaturated } \\
\mathrm{C}_{22}\end{array}$ \\
\cline { 2 - 11 } & 2.4 & 41.7 & 0 & 7.7 & 5.4 & 10.6 & 0 & 2.6 & 10.3 & 16.2 \\
$\begin{array}{l}\text { Mycobacteria grown } \\
\text { in the mouse lungs }\end{array}$ & & 37.5 & 0 & 9.5 & 1.6 & 2.2 & 0.9 & 3.2 & 13.9 & 22.7 \\
$\begin{array}{l}\text { Glass-adherent cells } \\
\text { of infected mouse lungs } \\
\text { Infected mouse serum }\end{array}$ & 3.1 & 0 & 19.3 & 2.1 & 6.3 & 24.2 & 32.3 & 2.0 & 3.3 & 5.8 & 4.9 \\
\hline
\end{tabular}

fatty acids were found to occupy around half of the total in any of the three samples. However, the esters of the glass-adherent cells and of the bacilli were distinct from that of the serum. In the formers, $\mathrm{C}_{20: 4}$ and unsaturated $\mathrm{C}_{22}$ were present in a fairly high proportion, but in the latter $\mathrm{C}_{18: 1}$ and $\mathrm{C}_{18: 2}$ were predominant. This observation was also interesting in connection with our previous finding with macrophage phospholipids that $\mathrm{C}_{20: 4}$ was a major fatty acid in phosphatidylethanolamine $(\mathbf{1 4 . 8 \%})$ and phosphatidylcholine $(14.1 \%)$ but it was not detected in lysophosphatidylcholine or cardiolipin (Kondo and Kanai, 1974).

According to Werb and Cohn (1972), cholesterol esters are taken up by macrophages with serum lipoprotein, especially into pinocytic vacuoles to be hydrolyzed into free forms by an active cholesterol esterase. Our present observation suggests, however, that the simple association of serum lipoproteins with the intracellular bacilli in such vacuoles do not always explain the presence of 


\section{TABLE III}

Fatty acid patterns of the upper and lower parts of the cholesterol ester spot on TLC plate* obtained from the neutral fat fraction of M. bovis (Ravenel) grown in the mouse lungs

\begin{tabular}{lcccccccccc}
\hline \multirow{2}{*}{$\begin{array}{l}\text { Cholesterol } \\
\text { ester spot }\end{array}$} & $\mathrm{C}_{14: 0}$ & $\mathrm{C}_{16: 0}$ & $\mathrm{C}_{16: 1}$ & $\mathrm{C}_{18: 0}$ & $\mathrm{C}_{18: 1}$ & $\mathrm{C}_{18: 2}$ & $\mathrm{C}_{20: 0}$ & $\mathrm{C}_{20: 1-3}$ & $\mathrm{C}_{20: 4}$ & Unsaturated \\
\cline { 2 - 10 } & 3.7 & 47.5 & trace & 8.5 & 7.4 & 12.5 & 1.2 & 0 & 6.7 & 10.8 \\
\hline Upper part & 3.9 & 26.3 & 1.0 & 7.6 & 3.0 & 11.9 & 3.5 & 4.7 & 14.1 & 18.6 \\
Lower part & 1.9 &
\end{tabular}

* Silica gel G plate developed with heptane:ether:acetic acid (90:10:1).

cholesterol esters in the in vivo bacilli.

Table III shows fatty acid patterns of cholesterol esters when the upper and lower parts of the corresponding gel were scraped off separately and examined. A greater distribution of $\mathrm{C}_{20: 4}$ and unsaturated $\mathrm{C}_{22}$ in the lower part of the spot is demonstrated in the table.

\section{REFERENCES}

Asselineau, J. (1966): The bacterial lipids. Pub. Herman, Paris, $372 \mathrm{p}$.

Fleischer, S., Fleischer, B. AND Stoechnius, W. (1967): Fine structure of lipid-depleted mitochondria. J. Cell Biol., 32, 193-208.

KanAI, K. AND Kondo, E. (1970): Separation and properties of "in vivo grown tubercle bacilli" associated with the lysosomal membrane. Japan. J. Med. Sci. Biol., 23, 303-314.

KanaI, K. AND Kondo, E. (1971): Limits in tuberculosis chemotherapy as revealed by experimental study in mice. Japan. J. Med. Sci. Biol., 24, 313-321.

Kondo, E. AND KanaI, K. (1974): A comparative observation of cholesterol ester content between uninduced and induced mouse peritoneal exudate cells. Japan. J. Med. Sci. Biol., 27, 67-79.

Kondo, E. AND KANAI, K. (1976): Accumulation of cholesterol esters in macrophages incubated with mycobacteria in vitro. Japan. J. Med. Sci. Biol., 29, 123-137.

Kondo, E., KanaI, K., Nishimura, K. And Tsumita, T. (1970): Analysis of host-originated lipids associating with "in vivo grown tubercle bacilli". Japan. J. Med. Sci. Biol., 23, 315-326.

Kondo, E., MUrohashi, T., KaNAI, K. AND Kubota, S. (1971): Esterification of tissue cholesterol with fatty acids in the lungs of tuberculous mice. Japan. J. Med. Sci. Biol., 24, 345-356.

Werb, Z. ANd CoHn, Z. A. (1972): Cholesterol metabolism in the macrophages. III. Ingestion and intracellular fate of cholesterol and cholesterol esters. J. Exptl. Med., 135, 21-44.

YounGNER, J. S. AND NOLL, H. (1958): Virus-lipid interaction. I. Concentration and purification of viruses by adsorption to a cholesterol column and studies of the biological properties of lipid-adsorbed virus. Virology, 6, 157-180.

Department of Tuberculosis and The First Department of Bacteriology, National Institute of Health, Kamiosaki, Shinagawa-ku, Tokyo 141, Japan

(Received: January 27, 1977)
EIKo KONDO

KoomI KANAI

\begin{tabular}{ll}
\hline 近藤犖子（国立予防衛生研究所 結核部) \\
金井興美（国立予防衛生研究所 細菌第一部）
\end{tabular} 